\title{
Emprego, Trabalho e Renda no Brasil contemporâneo: desafios e potencialidades
}

\author{
Matheus Dums \\ Caroline Schmidt de Camargo ${ }^{2}$ \\ Recebido em março de 2021 \\ Aceito em junho de 2021
}

\section{RESUMO}

O objetivo do artigo é analisar a temática do Emprego, Trabalho e Renda, na situação atual do Brasil de Pandemia de Covid-19, demonstrando por meio de indicadores sociais a realidade e apontando o estado e criação de políticas públicas que impactem neste tema. Trata-se de uma análise teórico-crítica, pautada em uma pesquisa bibliográfica e documental. O artigo está configurado nos seguintes itens, são eles: Indicadores relacionados a Emprego, Trabalho e Renda; Breve histórico sobre a legislação acerca do Emprego, Trabalho e Renda; Dado dos Indicadores Sociais; Análise dos Dados; e Desafios e Potencialidades. Em suma, dos resultados da análise destaca-se que nesta crise social e econômica, o Estado com suas contrarreformas e atual gestão neoliberal, não garantem condições elementares para a vida humana, empobrecendo cada vez mais as camadas mais vulnerabilizadas da sociedade e aumentando a concentração de capital. O que impõe aos/às progressistas os desafios de sensibilizarem a população, se articularem e mobilizarem junto com esta, como forma de resistência e enfrentamento à contrarreforma do Estado, buscando qualidade de vida para todas as pessoas.

Palavras-chave: Indicadores Sociais. Desemprego. Desigualdades Sociais.

\section{Employment, labor and income in contemporary Brazil: Challenges and Potentialities}

\begin{abstract}
The objective of the article is to analyze the theme of Employment, Work and Income, in the current situation of the Covid-19 Pandemic in Brazil, demonstrating through social indicators the reality and pointing out the state and creation of public policies that impact on this theme. This is a theoreticalcritical analysis, based on bibliographical and documental research. The article is configured in the following items, they are: Indicators related to Employment, Work and Income; Brief background on legislation on Employment, Labor and Income; Social Indicators Data; Data analysis; and Challenges and Potentials. In short, from the results of the analysis, it is highlighted that in this social and economic crisis, the State with its counter-reforms and current neoliberal management, do not guarantee elementary conditions for human life, increasingly impoverishing the most vulnerable layers of society and increasing concentration of capital. This imposes on progressives the challenges of sensitizing the population, articulating and mobilizing along with it, as a form of resistance and confrontation against the State's counter-reform, seeking quality of life for all people.
\end{abstract}

\footnotetext{
${ }^{1}$ Graduando em Serviço Social pela Universidade Estadual de Ponta Grossa. Ponta Grossa-Paraná, Brasil. E-mail: mmatheusdums@gmail.com.

${ }^{2}$ Graduanda em Serviço Social pela Universidade Estadual de Ponta Grossa. Ponta Grossa-Paraná, Brasil. E-mail: carolineschmidt17@outlook.com.
} 
Keywords: Social Indicators. Unemployment. Social differences.

\section{Introdução}

No Brasil, tem-se vivido desde os últimos anos, especialmente a partir da última metade da década de 2010, um aumento do desemprego, do número de pessoas desalentadas e um aumento na proporção dos domicílios nas menores faixas de renda. A crise atual já havia iniciado antes mesmo da pandemia de Covid-19, sendo esta crise resultado da desaceleração do crescimento econômico de parceiros econômicos brasileiros, como Argentina e China, aliado às políticas neoliberais.

Uma das formas de se verificar os resultados das políticas públicas e a situação de bem-estar da população é através de indicadores sociais ${ }^{3}$, que permitem avaliar, comparar dados, traçar e efetivar estratégias que melhorem a vida da população. Uma importante temática de indicadores é referente ao Emprego, Trabalho e Renda ${ }^{4}$, que permitem verificar a situação de ocupação e de ganhos por família e, consequentemente, identificar o estado de bem-estar, visto que a renda é essencial para a sobrevivência em uma sociedade capitalista.

Por consequência, este trabalho tem por objetivo realizar uma análise dos indicadores sociais que demonstrem a situação do mercado de trabalho brasileiro dos últimos anos, inclusive, com dados do período da Pandemia de Covid-19, ao mesmo tempo que compara a situação atual de desemprego brasileiro com outros países. Referese a uma análise feita a partir de pesquisa bibliográfica e documental.

Primeiramente, é apresentado um breve histórico acerca da legislação do mundo do trabalho no Brasil. Posteriormente, são trazidos dados dos indicadores dos últimos anos sobre Ocupação e Renda, e uma análise sobre os mesmos. Formulou-se

\footnotetext{
3 Indicadores Sociais são medidas quantitativas contabilizadas a partir da realidade empírica, servem para dar sentido para um conceito abstrato. Compreendendo determinantes sociais de uma sociedade, permitindo, inclusive, mensurar a situação de Bem-Estar da população e os fenômenos sociais presentes. Para a partir dele apreender a realidade, podem ser utilizados os resultados a fim de estudos universitários e/ou dar embasamento para criação e avaliação de políticas públicas (JANNUZZI, 2017).

${ }^{4}$ As políticas de Emprego, Trabalho e Renda têm por função garanti-los, por meio de ações e programas integrados a partir de decisões da esfera pública, tendo como norte a garantia da cidadania através do trabalho (SANTOS, 2016).
} 
considerações acerca dos desafios e potencialidades presentes no Brasil, que se encontra na condição de um país capitalista dependente, que precariza ainda mais a sua classe trabalhadora, recaindo este ônus, principalmente, nas mulheres e na população negra (conforme os dados), o que aponta para a necessidade de políticas públicas mais eficientes.

\section{Breve histórico sobre a legislação acerca do Emprego, Trabalho e Renda}

O trabalho é direito social, expresso no Artigo $6^{\circ}$ da Constituição Federal de 1988 (BRASIL, 1988). A legislação e suas mudanças ocorrem após embates e disputas dentro da sociedade civil, que são transferidos para o interior do Estado, dando origem a leis, políticas públicas, dentre outras expressões. Desta forma, pode-se afirmar que a legislação e as políticas públicas acerca do emprego são frutos destas correlações de forças entre a sociedade e o Estado.

Dentre as leis que regulamentam a permissão, situação e condições de emprego, está o Estatuto da Criança e do Adolescente (ECA). O ECA, Lei n 8.069, permite o trabalho a partir dos 14 anos de idade, desde que seja na forma de menor aprendiz (BRASIL, 1990). Adolescentes que tenham menos de 16 anos e sejam maiores de 14 anos só podem trabalhar nesta modalidade (BRASIL, 1998).

A Consolidação das Leis do Trabalho (CLT) é uma das bases jurídicas que regulamenta a situação do emprego no Brasil. Aprovada pelo Decreto-lei $\mathrm{n}^{\circ} 5.452$ (BRASIL, 1943), a CLT vale para o/a trabalhador/a urbano/a que não realiza trabalhos eventuais e que seja remunerado por salário. Desta forma, ela não é aplicada ao/à trabalhador/a autônomo/a, trabalhadores/as rurais, por exemplo. A CLT garante o direito às férias, salário mínimo, estabelecimento de teto da jornada de trabalho e obrigação da pessoa empregada possuir Carteira de Trabalho e contribuir para a Previdência Social. Com esta última obrigação, garante-se renda ao/a trabalhador/a em decorrência de velhice, caso tenha atingido os requisitos mínimos, dentre outras garantias.

Em um momento de fortalecimento do Setor Privado e suas ideias neoliberais, inicia-se um processo de contrarreforma do Estado brasileiro no campo dos direitos 
sociais, tal como na Reforma Trabalhista de 2017, quando é instituído o trabalho intermitente (uma modalidade na qual o trabalho não é contínuo e a remuneração acontece de acordo com os dias trabalhados), e há a permissão de trabalho para mulheres grávidas em ambientes de insalubridade baixa e média (BRASIL, 2017).

No período da Pandemia, foram tomadas medidas desordenadas e fragmentadas por parte do Ministério da Economia em relação ao mercado de trabalho, como no caso da Medida Provisória 936 de 2020, que permitiu reduzir jornadas de trabalho e salários em até 3 (três) meses por meio de acordo individual (DOCA, 2020).

Percebe-se, desta forma, como os embates e discussões da sociedade civil moldam o Estado, e este, por sua vez, acaba por impactar na sociedade, nas relações de emprego e nas demais.

\section{Dados dos indicadores sociais}

Indicadores de Desocupação ${ }^{5}$, Ocupação ${ }^{6}$, Percentual de pessoas desalentadas7 na população na força de trabalho ${ }^{8}$ e da Taxa de participação na força de trabalho ${ }^{9}$, demonstram a situação do mercado de trabalho. Conforme Jannuzzi (2017), com base nesses indicadores é possível perceber o sucesso ou fracasso de políticas públicas na área

${ }^{5}$ A desocupação também é chamada de desemprego, está nesta condição quem está na idade de trabalhar, não possui trabalho e busca de forma ativa este na semana anterior à semana de referência (IBGE, 2020).

${ }^{6}$ Ocupação é a parte da população que possuem idade de trabalhar, tenham trabalhado pelo menos uma hora remunerada na semana de referência. Neste indicador estão inclusos assalariados/as com ou sem carteira assinada e trabalhadores/as por conta própria (IBGE, 2020).

7 Desalentados/as, são pessoas em idade de trabalhar que querem um emprego, que perderam as esperanças ou encontram dificuldades para se locomover e procurar um. Estão fora da força de trabalho e dentro da força de trabalho potencial (IBGE, 2020).

${ }^{8}$ Nela se encontram as pessoas em idade de trabalho e apenas os/as ocupados/as e desocupados/as, não fazendo parte deste indicador as pessoas fora da força de trabalho e suas divisões (Força de trabalho potencial, Fora da força de trabalho potencial e as seguintes) (IBGE, 2020).

9 A partir da população total, há a divisão da população entre maiores e menos de 14 anos, e as derivações de outros indicadores. Está divisão demonstra quem está ou não na idade de trabalhar (maiores e menores de 14 anos), das pessoas que estão em idade de trabalho há a divisão entre Pessoas na Força de Trabalho e Pessoas fora da força de Trabalho, na primeira divisão estão as pessoas que procuram trabalho (desocupadas/desempregadas) e pessoas ocupadas (empregadas), na segunda parte da divisão possui os grupos não pertencentes à Força de trabalho Potencial, e é dentro das divisões dentro deste grupo que se encontram os/as Desalentados/as (IBGE, s.d.). 
econômica, bem como a possível deterioração, ou não, da qualidade de vida em decorrência da falta de renda.

A tabela 1, exposta abaixo, aborda estes indicadores, nos trimestres de outubro, novembro e dezembro de 2019; julho, agosto e setembro de 2020; outubro, novembro e dezembro de 2020.

\section{Tabela 1 - Indicadores em relação ao emprego e trabalho do Brasil no Trimestre móvel: out-nov-dez/2020 (em porcentagem)}

\begin{tabular}{|c|c|c|c|c|}
\hline \multirow[b]{2}{*}{ Indicadores } & & \multicolumn{3}{|c|}{ Estimativa dos trimestres móveis } \\
\hline & & $\begin{array}{l}\text { out-nov-dez } \\
2019\end{array}$ & $\begin{array}{l}\text { Jul-ago-Set } \\
2020\end{array}$ & $\begin{array}{l}\text { out-nov-dez } \\
2020\end{array}$ \\
\hline Taxa de desocupação & 11 & 14,6 & \multicolumn{2}{|l|}{13,9} \\
\hline \begin{tabular}{|lr|}
\multicolumn{2}{|l|}{ Nível da ocupação } \\
Percentual de & pessoas \\
desalentadas & na \\
população & \\
\end{tabular} & 55,1 & 47,1 & \multicolumn{2}{|l|}{48,9} \\
\hline $\begin{array}{l}\text { na força de trabalho ou } \\
\text { desalentadas }\end{array}$ & 4,2 & 5,7 & \multicolumn{2}{|l|}{5,5} \\
\hline $\begin{array}{l}\text { Taxa de participação na } \\
\text { força de trabalho }\end{array}$ & 61,9 & 55,1 & \multicolumn{2}{|l|}{56,8} \\
\hline
\end{tabular}

Fonte: IBGE. Indicadores para população de 14 anos ou mais de idade. Referência aos meses de outubro, novembro e dezembro de 2020. PNAD Contínua. Rio de Janeiro, 2021. Disponível em: $<$ https://cutt.ly/5xsEPou>. Acesso em: 03 mar. 2021.

Nota: Elaboração própria

Todos os indicadores da Tabela 1, com exceção do Nível de ocupação e da Taxa de participação na força de trabalho, tiveram aumento entre o último trimestre de 2019 e o de 2020. O inverso aconteceu entre o penúltimo trimestre de 2020 e o último do mesmo ano, havendo uma diminuição da Taxa de desocupação e do Percentual de pessoas desalentadas, e aumento do Nível de ocupação e da Taxa de participação na força de trabalho. Assim, o saldo em pontos percentuais entre o último trimestre de 2019 e o de 2020, teve o seguinte resultado: a Taxa de desocupação aumentou 2,9\%; o Nível de ocupação caiu 6,2\%; o Percentual de pessoas desalentadas na população na força de 
trabalho ou desalentadas aumentou 1,3\% e a Taxa de participação na força de trabalho recuou 5,1\% (IBGE, 2021).

Ainda em relação à taxa de desocupação do último trimestre de 2020, a taxa foi maior entre mulheres e a população negra. Segundo o IBGE (2021), a taxa de desocupação em relação ao sexo foi de 16,4 \% para as mulheres e 11,9\% para os homens, e, de acordo com a cor ou raça, foi de $11,5 \%$ para os brancos, $15,8 \%$ para os pardos e $17,2 \%$ para os pretos.

Em relação à renda, o estudo do IPEA com os dados da PNAD COVID-19, classificou, proporcionalmente, domicílios em 7 (sete) faixas de renda, no primeiro trimestre dos anos de 2018, 2019, 2020, e também no quarto trimestre de 2019. Realça-se que entre o primeiro trimestre de 2018 e o primeiro de 2020 há aumento na proporção de domicílios nas três faixas de renda mais baixas, principalmente na faixa mais baixa, que é faixa de domicílios sem renda do trabalho, com um aumento de 4,41\%, desta forma, chegando a $23,48 \%$ dos domicílios. Ao mesmo tempo que a faixa de renda mais alta, a de Renda Alta $^{10}$, teve um aumento de $0,18 \%$, configurando 2,19 \% do total de domicílios (CARVALHO, 2020).

Esta situação não é um acaso, ou algo natural, é fruto de um processo histórico decorrente de escolhas políticas acerca da regulamentação do emprego e da falta de políticas públicas para aquecer o mercado de trabalho. Ficando nítido que as contrarreformas neoliberais aumentam a pobreza e acentuam as desigualdades sociais.

\subsection{Análise dos dados}

Entre meados da década de 2000 e 2014 pode ser observada uma progressiva queda na taxa de desocupação, além de um aumento significativo da proporção de trabalhadores formais, que passou de 44,6\% em 2002, para 56,9\% em 2012 (IBGE, 2013). Porém, nos anos seguintes, estes resultados foram revertidos completa ou parcialmente,

\footnotetext{
${ }^{10}$ Se enquadra em renda alta, quem teve renda domiciliar em maio de 2020 maior que $\mathrm{R} \$ 16.5009,66$ (CARVALHO, 2020).
} 
apesar de o ano de 2019 ter apresentado relativa melhora em relação ao ano anterior (IBGE, 2020).

Segundo Baltar (2014), houve na década de 2000 uma forte alta dos preços de grande parte de produtos considerados matérias primas, os chamados commodities, que representam mais da metade das exportações brasileiras, aliada a uma tendência à baixa dos preços internacionais de produtos manufaturados, o que contribuiu para manter baixa a inflação internacional. Este cenário contribuiu para uma maior atividade econômica e menor inflação no país, e o crescimento do PIB foi reforçado por uma política de estímulo ao crescimento e de redistribuição de renda comandada pelo Partido dos Trabalhadores, que acentuou a onda de expansão do consumo que começou em 2004.

O maior legado do governo Lula (2003 a 2010) é, sem sombra de dúvida, a geração de emprego e a consequente geração ou aumento da renda. Um fator positivo também é a chamada qualificação do mercado de trabalho, o que se deve a políticas educacionais que incentivaram e ampliaram o acesso da população ao ensino superior. Outro fator importante é a criação de uma política de transferência de renda, o Bolsa Família, com a finalidade de combater a miséria e promover a emancipação das famílias mais pobres.

Esse crescimento que o país viveu apenas foi desacelerado em partes em 2008 diante da crise econômica mundial, tendo nova queda após 2014, quando tem início no país uma forte crise político-econômica, período em que a taxa de desocupação sofre um grande aumento, como pode ser demonstrado pelo gráfico a seguir (Gráfico 1): 
Gráfico 1 - Taxa de desocupação das pessoas de 16 anos ou mais de idade, segundo o sexo - Brasil - 2012-2016

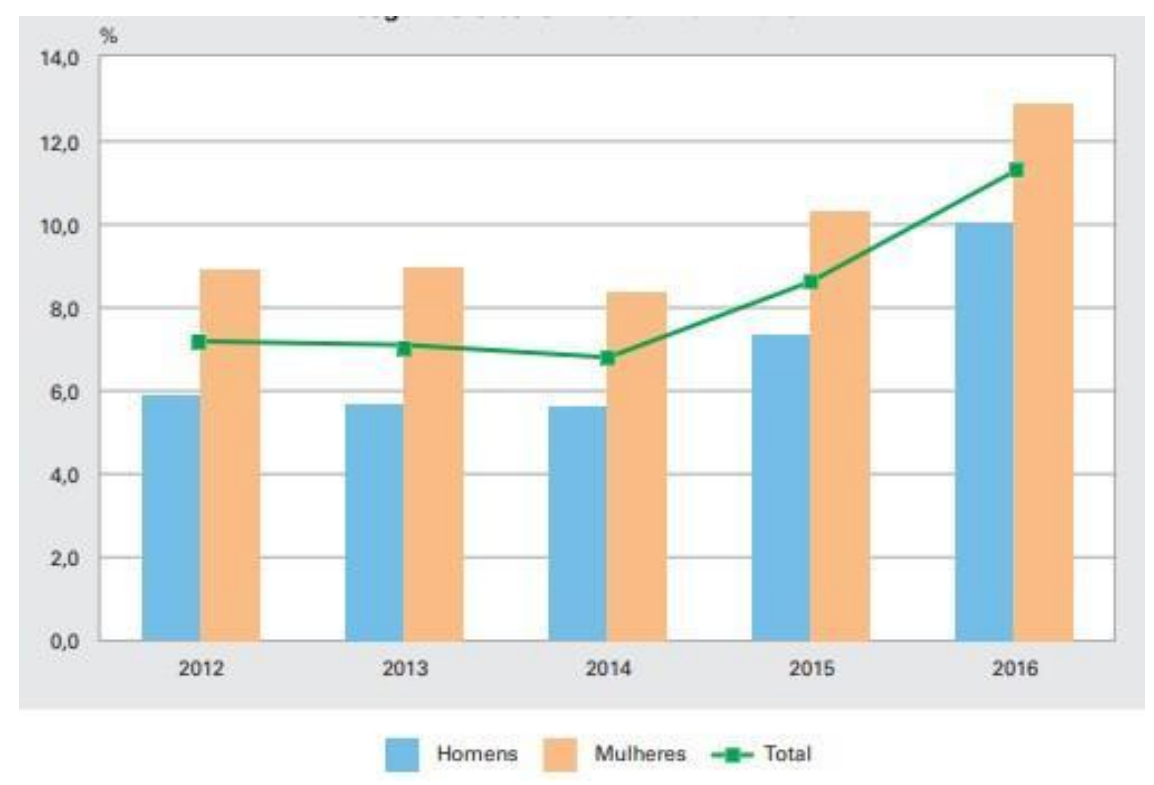

Fonte: IBGE. Síntese de Indicadores Sociais: Uma análise das condições de vida da população brasileira 2017. Rio de Janeiro, 2017. Disponível em: $<$ https://biblioteca.ibge.gov.br/visualizacao/livros/liv101459.pdf>. Acesso em: 10 mar. 2021.

Em 2016, após o impeachment que levou Michel Temer à presidência, começam a ser adotadas políticas que têm impacto direto não apenas no mercado de trabalho e na renda, mas na qualidade de vida dos cidadãos e nos seus direitos, como as privatizações, a implementação de um teto de gastos públicos, além de afetar diretamente o trabalhador e sua renda através de reformas trabalhistas e previdenciárias.

O gráfico a seguir (Gráfico 2) demonstra a evolução histórica de três indicadores utilizados na avaliação do mercado de trabalho: o nível de ocupação, a taxa de desocupação e a taxa de subutilização, que mede, além da taxa de desocupação, a taxa de desemprego oculto, que é formada pelos indivíduos que não buscaram emprego ativamente nos últimos 30 dias por desalento (desesperança) ou por estarem exercendo uma atividade irregular (bicos). O gráfico demonstra as informações anteriores, na qual o Brasil tem, até 2014, uma diminuição das taxas de desocupação e o seu aumento gradativo após esta data, continuando a crescer até 2019, quando sofre uma leve melhora: 


\section{Gráfico 2 - Nível de ocupação, taxa de desocupação e taxa composta de subutilização da força de trabalho - Brasil - 2012-2019}

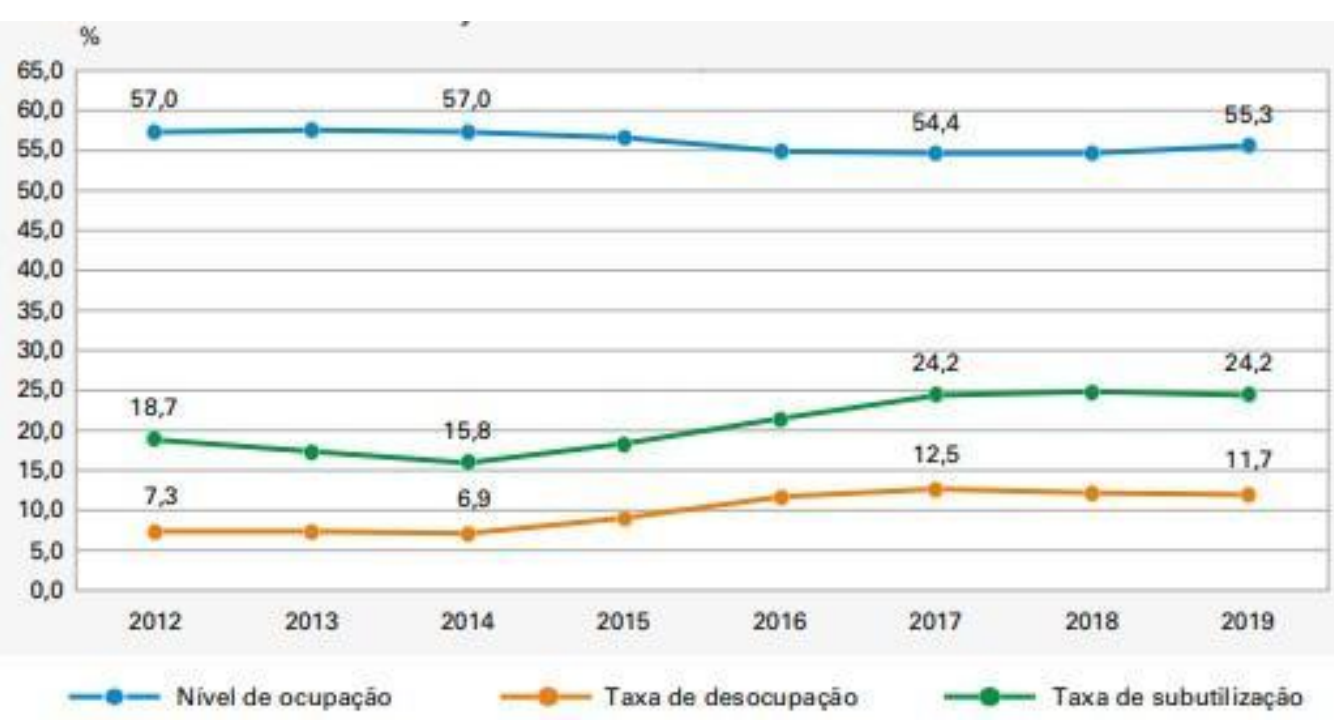

Fonte: IBGE. Síntese de Indicadores Sociais: Uma análise das condições de vida da população brasileira 2020. Rio de Janeiro, 2020. Disponível em: <https://biblioteca.ibge.gov.br/visualizacao/livros/livio176o.pdf>. Acesso em: 10 mar. 2021.

Apesar de apresentar aumento na taxa de ocupação, é preciso atentar-se às condições do trabalho e aos altos índices de ocupação informal. Desta forma, o aumento do número de pessoas ocupadas neste período não representa, necessariamente, um aspecto positivo da realidade, visto que os trabalhadores informais não têm seus direitos garantidos e estão muito mais vulneráveis e sujeitos a terem sua renda afetada pelos riscos inerentes ao mercado de trabalho, como doenças, incapacidades temporárias ou definitivas, e até mesmo o desemprego (IBGE, 2020).

Há fatores externos que também vem impactando a economia brasileira, e consequentemente na questão do trabalho, como a desaceleração econômica mundial, especialmente da China e Argentina. Em relação à China, esta vem obtendo nos últimos 6 (seis) anos, os piores resultados desde 1990 (FERREIRA, 2016; SANTIRO, 2020). É importante lembrar que a China é a principal parceira econômica do Brasil. Também há a crise instaurada nos últimos anos na Argentina, que impacta principalmente as exportações do Setor Industrial brasileiro (MATOS, 2019).

Dizer que o aumento da taxa de desemprego no Brasil em 2020 foi apenas devido a Pandemia é um equívoco. É o que mostra Herédia (2020) a partir de dados do Fundo Monetário Internacional (FMI), pois já em 2019 o Brasil apresentava uma taxa de 
desemprego de $11,9 \%$, bastante superior se comparada aos países desenvolvidos, que era de 5,4\%, ou mesmo com a América Latina, que era de 7,3\%. Tais taxas de desemprego aumentaram em todos estes locais em 2020, chegando, no Brasil a 14,7\%, em países desenvolvidos a 8,4\% e na América Latina a 9,3\%.

\section{Desafios e potencialidades}

Estes dados são resultados de fatores externos e internos do Brasil, que são interligados. Devido a economia brasileira ser voltada, principalmente, às exportações de produtos primários, os impactos da economia global refletem nas condições internas do país. E, como demonstra Florestan Fernandes (1975), as heranças coloniais que vem se atualizando em modernizações arcaicas dentro do capitalismo dependente brasileiro, não permitem que o país desenvolva um mercado interno mais forte, realizando uma superexploração da mão de obra, como no caso da população negra e das mulheres. Fortalecimento do mercado interno e outras ações por parte do Estado poderiam fazer com que impactos econômicos externos fossem amenizados, mantendo a renda e o consumo ao mesmo tempo que se assegura os empregos.

Dada a situação de desemprego, desalento e outros indicadores que demonstram a subutilização da força de trabalho, é necessário investimento em diversas áreas pelo Estado. Como demonstram Cardoso e Lima (2008), gastos autônomos (endógenos) têm um efeito multiplicador, pois o setor que recebe o investimento aumenta a receita e gasta em outros setores e, assim, aumentando o consumo, fazendo com que essa demanda faça o mercado abrir postos de trabalho, além dos empregos que podem ser gerados de forma direta. Este gasto inicial é menor do que a renda total gerada neste processo.

É isto o que acontece com o auxílio emergencial brasileiro criado na Pandemia de Covid-19 em 2020, que além de garantir o sustento de muitas famílias, também auxiliou na diminuição da crise atual. É o que Roubicek (2021) apresenta, citando o estudo do Centro de Pesquisa em Macroeconomia das Desigualdades da FEA-USP. Mas pode-se ir além, criando por meio de decisão política estatal, uma Renda Básica Universal, o que garantiria para todos/as cidadãos/ãs, independente de sua condição econômica e social, proteção social por meio de renda. 
Um dos programas que tem potencialidade de gerar emprego (direta e indiretamente) e renda é o Programa de Aceleração do Crescimento (PAC) criado em 2007, o qual promove, através do planejamento, obras de grande porte de infraestrutura social, urbana, logística e energética do país, auxiliando do desenvolvimento econômico e social, além de ter um papel fundamental no enfrentamento da crise de 2008 por auxiliar na manutenção dos empregos e da renda de brasileiros/as (BRASIL, s.d.). Porém, desde 2014, o programa vem sofrendo sucessivos cortes, em que o valor destinado à obras diminuiu 52\% de 2014 a 2018, além de medida realizada em 2019 não permitir a incorporação de novos projetos no PAC (LUPO, 2019).

O aumento de investimentos por parte do Estado brasileiro, por meio da retomada do PAC e da criação de uma Renda Básica Universal, dentre outras possibilidades, são alternativas para promover emprego e renda. Desta forma, faz-se urgente a revogação da Emenda Constitucional 95 (EC/95) de 2016 (BRASIL, 2016), que congelou investimentos públicos por 20 anos. Para que isso aconteça, é necessário mobilização popular, que se daria através de protestos e atos políticos, organização e ações em movimentos sociais, dentre outras formas, almejando resistir à desproteção e à não garantia de direitos por parte do Estado, ao mesmo tempo que se busca o atendimento das necessidades da população. À médio prazo, uma alternativa é a busca pela expansão de atores progressistas na sociedade política, ou seja, pessoas que têm como valores a democracia, a liberdade e a justiça social.

\section{Considerações finais}

A realização do trabalho reafirmou a importância do estudo dos indicadores sociais sobre Emprego, Trabalho e Renda para analisar a realidade brasileira e os resultados das políticas públicas sobre esse tema.

Diante da crescente desigualdade e das altas taxas de desemprego, fazem-se necessárias políticas de emprego que reconheçam as desigualdades de classe, gênero, raça, orientação sexual e, da exclusão da sociedade capitalista, das pessoas com deficiência, com o propósito de diminuí-las e desta forma atuar diretamente na renda e na emancipação das pessoas, principalmente as mais desfavorecidas economicamente e 
desprotegidas pelo mercado de trabalho, que são as que mais sofrem com os impactos da crise, como demonstrado no trabalho.

A compreensão desta realidade a partir de um compromisso ético com a emancipação humana, demonstra a necessidade de intervenção na realidade em vários sentidos. Mas para estas ações acontecerem é necessário haver uma maior mobilização e reivindicação popular acerca do tema Emprego, Trabalho e Renda, o que, dentre outras coisas, necessita da articulação e sensibilização por parte dos/as progressistas. A sensibilização poderá aumentar o número de atores políticos progressistas no Estado, que aliados com a pressão popular, poderão buscar expandir investimentos públicos e, ao mesmo tempo, superando impeditivos para estes, como por meio da revogação da EC/95 de 2016. Desta forma, deverão garantir a criação e a efetividade de políticas públicas, como a Renda Básica, voltadas para a redução das desigualdades sociais.

\section{Referências}

BRASIL. Constituição (1988). Constituição da República Federativa do Brasil [recurso eletrônico]. Brasília: Supremo Tribunal Federal, Secretaria de Documentação, 2019. 530 p. Atualizada até a EC n. 105/2019. Disponível em:< https://www.stf.jus.br/arquivo/cms/legislacaoConstituicao/anexo/CF.pdf>. Acesso em: 04 mar. 2021.

. Consolidação das Leis do trabalho. Decreto-lei oㅜ 5.452, de 1o de maio de 1943. Aprova a Consolidação das Leis do Trabalho. Brasília-DF, 1943. Disponível em: <http://www.planalto.gov.br/ccivil_o3/decreto-lei/del5452.htm>. Acesso em: 04 mar. 2021.

Decreto № 76.403, de 8 de outubro de 1975. Cria o Sistema Nacional de Emprego (SINE) e dá outras providências. Brasília-DF, 1975. Disponível em: <http://www.planalto.gov.br/ccivil_o3/decreto-lei/del5452.htm> . Acesso em: 04 mar. 2021.

Emenda Constitucional $\mathrm{n}^{\circ}$ 2o, de 15 de dezembro de 1998. Modifica o sistema de previdência social, estabelece normas de transição e dá outras providências. DOU de 16.12.1998. Brasília, DF. Disponível em: <http://www.planalto.gov.br/ccivil_03/constituicao/emendas/emc/emc2o.htm>. Acesso em: 04 mar. 2021. 
Emenda Constitucional no 95, de 15 de dezembro de 2016. Altera o Ato das Disposições Constitucionais Transitórias, para instituir o Novo Regime Fiscal, e dá outras providências. Diário Oficial da União, Brasília, DF, 15 dez. 2016. Disponível em: < https://cutt.ly/UxsE3wm>. Acesso em: 05 mar. 2021.

Estatuto da Criança e do Adolescente. Lei n 8.069, de 13 de julho de 1990. Câmara dos Deputados, Lei no 8.069, de 13 de julho de 1990. DOU de 16/07/1990 - ECA. Brasília, DF. Disponível em: <http://www.planalto.gov.br/ccivil_03/leis/l8o69.htm>. Acesso em: 04 mar. 2021.

Lei no 13.467, de 13 de julho de 2017. Disponível em: <http://www.planalto.gov.br/ccivil_03/decreto-lei/del5452.htm>. Acesso em: 04 mar. 2021.

MINISTÉRIO DO PLANEJAMENTO. Sobre o PAC. [s.d.]. Disponível em: <http://pac.gov.br/sobre-o-pac>. Acesso em: 05 mar. 2021.

BALTAR, Paulo. Política econômica, emprego e política de emprego no Brasil. Estud. av., São Paulo, v. 28, n. 81, p. 95-114, Agosto 2014. Disponível em: <http://www.scielo.br/scielo.php?script=sci_arttext\&pid=S0103-40142014000200007 \&lng=en\&nrm=iso $>$. Acesso em: 10 mar. 2021.

BARBOSA, A. L. N. H.; COSTA, J. S.; HECKSHER, M. MERCADO DE TRABALHO E PANDEMIA DA COVID-19: AMPLIAÇÃO DE DESIGUALDADES JÁ EXISTENTES?. Instituto de Pesquisa Econômica Avançada (IPEA). Ministério da Economia. Mercado de Trabalho. 2020. Disponível em: <http://repositorio.ipea.gov.br/handle/11058/10186.> Acesso em: 10 mar. 2021.

CARDOSO, F. G.; LIMA, G. T. A concepção de Keynes do sistema econômico como um todo orgânico complexo. Econ. soc., Campinas, v. 17, n. 3, p. 359-381, Dez. 2008. Disponível em: <http://www.scielo.br/scielo.php?script=sci_arttext\&pid=So104o6182008000300001 \&lng=en\&nrm=iso $>$. Acesso em: 05 mar. 2021.

CARVALHO, S.S. Os efeitos da pandemia sobre os rendimentos do trabalho e o impacto do auxílio emergencial: o que dizem os microdados da PNAD covid-19. Instituto de Pesquisa Econômica Aplicada (IPEA), Ministério da Economia. Carta de Conjuntura número 48, $3^{\text {o }}$ trimestre 2020, 18 páginas. 02/07/2020. Disponível em: <https://www.ipea.gov.br/portal/images/stories/PDFs/conjuntura/200826_cc48_result ados_pnda_julho.pdf>. Acesso em: 05 mar. 2021.

DOCA, G. MP 936: acordos de redução de salário e suspensão de contrato de trabalho já chegam a 3,5 milhões. O Globo. 23 abr. 2020. Disponível em: $<$ https://oglobo.globo.com/economia/mp-936-acordos-de-reducao-de-salario-suspen sao-de-contrato-de-trabalho-ja-chegam-35-milhoes-1-24389615>. Acesso em: 11 mar. 2021. 
IBGE. Desemprego. Brasília - DF, S.D. Disponível em: <https://www.ibge.gov.br/explica/desemprego.php>. Acesso em: 03 mar. 2021.

. Indicadores para população de 14 anos ou mais de idade. Referência aos meses de outubro, novembro e dezembro de 2020. PNAD Contínua. Rio de Janeiro, 2021. Disponível em: https://cutt.ly/5xsEPou. Acesso em: 03 mar. 2021.

. Pesquisa Nacional por Amostra de Domicílios PNAD COVIDig.

Julho/2020. Coordenação de Trabalho e Rendimento. Pesquisa Nacional por Amostra de Domicílios (PNAD Contínua). Instituto Brasileiro de Geografia e Estatística (IBGE). Rio de Janeiro, 2020. Disponível em: <https://biblioteca.ibge.gov.br/visualizacao/livros/livio1745.pdf>. Acesso em: 03 mar. 2021.

. PNAD Contínua Trimestral: desocupação recua em cinco das 27 UFs no $4^{\circ}$ trimestre de 2020. Sala de imprensa. [s.l.], 2021. Disponível em: $<$ https://agenciadenoticias.ibge.gov.br/agencia-sala-de-imprensa/2013-agencia-de-n oticias/releases/30236-pnad-continua-trimestral-desocupacao-recua-em-cinco-das-2 7ufs-no-4-trimestre-de-2020>. Acesso em: 11 mar. 2021.

Síntese de Indicadores Sociais: Uma análise das condições de vida da população brasileira 2017. Rio de Janeiro, 2017. Disponível em: <https://biblioteca.ibge.gov.br/visualizacao/livros/livio1459.pdf>. Acesso em: 10 mar. 2021

Síntese de Indicadores Sociais: Uma análise das condições de vida da população brasileira 2020. Rio de Janeiro, 2020. Disponível em: https://biblioteca.ibge.gov.br/visualizacao/livros/liv10176o.pdf. Acesso em: 10 mar. 2021.

FERNANDES, F. Capitalismo Dependente: Classes Sociais na América Latina. 2. ed. Rio de janeiro: Zahar Editores, 1975. Disponível em: $<$ https://democraciasocialista.org.br/wp-content/uploads/2020/o7/Capitalismoeclasses-na-AmLat-Florestan.pdf $>$. Acesso em: 02 fev. 2021.

FERREIRA, A. Desaceleração da China afeta empresas, dólar e inflação; entenda. UOL, 19 jan. 2016. Disponível em: <https://economia.uol.com.br/noticias/redacao/2016/o1/19/desaceleracao-da-china-a feta-empresas-dolar-e-inflacao-no-brasil-entenda.htm>. Acesso: 10 mar. 2021.

HERÉDIA, T. Desemprego vai crescer no mundo, mas subirá ainda mais no Brasil.

CNN. [S.l.], 2020. Disponível em: <https://www.cnnbrasil.com.br/business/2020/o5/o7/desemprego-vai-crescer-no-mun do-mas-subira-ainda-mais-no-brasil>. Acesso em: 11 mar. 2020.

JANNUZZI, P.M. Indicadores Sociais no Brasil: Conceitos, Fontes de Dados e Aplicações. 6. ed. Campinas-SP: Alínea, 2017. Disponível em: 
<https://www.researchgate.net/publication/33634876o_Indicadores_Sociais_no_Brasil _conceitos_fonte_de_dados_e_apicacoes>. Acesso em:3 mar. 2021.

LUPO, F. Marco de gestões petistas, PAC deixará de receber novos projetos. Folha de São Paulo, Edição São Paulo/Distrito Federal, 30 jul. 2019. Disponível em: $<$ https://acervo.folha.com.br $/$ leitor.do?numero $=48830 \&$ anchor $=6125161$ \&origem $=$ bus ca\&originURL=\&pd=b39906a9384c0045946994b125175475>. Acesso em 05 mar. 2021.

MATOS, S. Desa celeração global atinge indústria e investimento, piorando cenário para o Brasil, diz economista. [Entrevista concedida a] Vinicius Neder. O Estado de S.Paulo, 15 ago. 2019. Disponível em: $<$ https://economia.estadao.com.br/noticias/geral,desaceleracao-global-atinge-industri a-e-investimento-piorando-cenario-para-o-brasil-diz-economista,70002969068> .

Acesso em: 10 mar. 2021.

ROUBICEK, M. Os efeitos do auxílio emergencial no PIB, segundo este estudo. Nexo Jornal. Economia. [S.l.], 2021. Disponível em: < https://cutt.ly/NxsRa2w>. Acesso em: 05 mar. 2021.

SANTOS, A. H. S. As políticas ativas de emprego, trabalho e renda. Fundação Perseu Abramo. [S.1.], 2016. Disponível em: <https://fpabramo.org.br/2016/o4/11/as-politicasativas-de-emprego-trabalho-e-renda/ >. Acesso em: 05 mar. 2021.

SANTIRO, J. China cresce 6,1\% em 2019, a menor em 29 anos. El País. [S.l.], 17 jan. 2020. Disponível em: < https://cutt.ly/YxsRxpv>. Acesso em: 10 mar. 2021. 